\begin{tabular}{c} 
Volume and Issues Obtainable at Center for Sustainability Research and Consultancy \\
Journal of Business and Social Review in Emerging Economies \\
ISSN: 2519-089X \& ISSN (E): 2519-0326 \\
Volume 7: Issue 4 December 2021 \\
JSRᄃ \\
Journal homepage: www.publishing.globalcsrc.org/jbsee \\
\hline $\begin{array}{c}\text { Profit } \\
\text { PSlanet }\end{array}$
\end{tabular}

\title{
Food Security and Conflict Nexus: An Empirical Evidence from South Asian Region
}

Muhammad Zubair, Institute of Business Management, Karachi, Pakistan

*Ayesha Shoukat, Department of Commerce, The Islamia University Bahawalpur, Pakistan

Samreen Ramzan, Department of Commerce, The Islamia University Bahawalpur, Pakistan

*Corresponding author's email: ayesha.shoukat@iub.edu.pk

ARTICLE DETAILS

History

Revised format: Nov 2021

Available Online: Dec 2021

Keywords

Food Security, Dietary

Energy Supply, Conflict,

Fix Effect, South Asia

\section{JEL Classification}

L66, $Q 18$
Purpose: This emprical study aims to find the plausible link of food security and conflict for six conflict affected south asian countries durng 1990-2017.

Design/Methodology/Approach: Using the data from FAO for Dietary Energy Supply (DES) a proxy for food security and battled deaths for Conflict from Uppsala conflict database a panel of six south Asian countries has been analyzed. Using fix effect model.

Findings: The results reveal that conflict in selected sample of south Asian countries is negatively associated with food security as the onset of conflict the calories intake (kca/day/capita) decrease 26 on average in year. The results might be consistent with some recent empirical studies investigating the same relationship from other regions of the world.

Implications/Originality/Value: The empirical literature explaining this nexus of food security and conflict has been analyzed on the date from single country affected by conflict. Fewer studies investigate this relation which is based cross countries analysis.

(C) 2021 The authors, under a Creative Commons Attribution-

NonCommercial 4.0

Recommended citation: Zubair, M., Ayesha, S. and Samreen, R. (2022). Food security and conflict Nexus an Empirical evidence from south Asian region. Journal of Business and Social Review in Emerging Economies, 7 (4), 917-925.

\section{Introduction}

The Food insecurity is emerged as grave concern which affects the lives of millions across the globe. It has potential implications for the issues like poverty, health, and nutrition etc. According the FAO report "The state of food security and Agriculture (FAO 2019) more than 820 million people around the globe were still hungry in 2018 despite the fact number of hungry people is increasing slowly. The report further states that more than 2 billion people don't have access to safe, nutritious and sufficient food while around 149 million children were stunted across the globe till 2018. The factors such as Low level of income, unequal distribution of wealth, Unemployment, declining farm size, Social discrimination, Population growth, Poverty and Political instability etc. are substantially contributing in rising food insecurity in the world particularly in developing countries. 
Apart from all these contributors, the conflict can also have considered to be a potential factor having serious implications about the food insecurity of highly volatile conflict affected regions of the world. (Cindy Holleman, 2017) states that 19 countries which currently classified by FAO as being in a prolonged food crisis currently affected by conflict also. (FAO 2019) reveal that in the contexts of food crises, the linkage of conflict with economic slowdowns is substantial. The Conflict and insecurity of civilians were the main drivers of food insecurity in 21 states during 2018. Although it could be possible that the food security and conflict could be endogenous or exogenous factors of each other but most of the existing literature on food security and conflict nexus suggests that food insecurity might be an outcome of conflict. (Teodosijevic, 2003) suggests that conflict might be a determinant of food security due to the massive destruction of agricultural resources and the disruption of markets. On the other hand, food insecurity might be a cause of conflict because it can fuel the economic and social grievances to turn into conflict.

Since the WWI most of conflict of the world fought in less developed regions particularly in Africa and Asia so these regions have potential implications of conflict in account of food security. African region in this regard has been discussed in literature on food security and conflict nexus but the Asian region in general and south Asian in particularly found to be less explained region despite its emergence as epicenter of the global conflicts at the end of last century. Long standing unresolved conflict in Kashmir, the invasions in Afghanistan, the terrorism in Pakistan, civil war Sri Lanka and conflicts fueled by political instability in almost all countries of the region evidently prove that this region might be one of the highly volatile region of the world in terms of conflict. South Asian region has been worst affected region as the majority of the poor, and the food-insecure people living in this region which has been characterized by malnutrition, stunting and wasting. FAO 2019 states that despite the decline in prevalence of undernourishment from $22 \%$ to $15 \%$ in last five years it is still the as compare to the other sub regions of Asia.

The empirical literature based on south Asia in account of interaction between food security and conflict can be scarily traced. Only few studies such as (Anna D’Souza, 2012) found to be accesible which covers the south asian countries in contaxt of food security conflict nexus based on analysis of sigle country rather than the panel of regional countries. This study aims to bridge this gap in empirical litaerature by investigating the plausible link of food security and conflict for six south asian countries including Afghanistan, Pakistan, India, Bangladesh, Nepal, and Sri Lanka which have experinced conflict since 1990s or still have the ongoing conflict. Morever some countries out of selected sample declared as food insecure by FAO. So considering this the study will investigate whether the food security is affected by conflict in south Asia? The study is orgnised in following order. Section II and III of the study explain the concepts of food security and conflict respectively. Section III describes the theoretical and empirical literature about the interaction between food security and conflict, section IV explains the methodology which includes data and econometric model followed by results and discussion. The last part concludes the study and suggest pathway for further research.

\section{Food Security}

Food security seems to be a complex phenomenon which might be associated with production, distribution, accessibility, utility and sustainability of food resources. Various organizations like Food and Agricultural organization (FAO) of United Nations, and World Bank etc. establishing their own standards, have defined the food security. The most of researchers and policy makers working in this area use these standardized definitions to explore different dimensions of food security. As per the defined by World Bank the food security is an access by all people at all times to plenty of food for active and healthy life. Similarly, Food and Agriculture Organization (FAO 1996) defines food security as a situation that exists when all people, at all times, have physical, social and economic access to sufficient, safe and nutritious food that meets their dietary needs and food preferences for an active and healthy life. The FAO's definition for food security has been widely considered to use in literature as it 
seems to be comprehensively incorporating several needs including the availability and access to food, which is culturally appropriate. (Barrett, 2010) states that in today's global environment many factors exacerbate food security. We are growing and producing food which is enough to feed the world's population. But this food is not distributed nor has the global community culturally appropriate across to this food. The Locally available food access differs dramatically and the greatest difference exists between developed and developing countries. The main reason behind this food inequity is an income disparity among different segments of population. (Karyn Havas, 2011) Explain that nutrition and health are directly related to food security. Usually, food security being taken as related to the availability and access of food but it might be threatening by the other factors such income disparity, urbanization, overpopulation, degradation, ecosystem and animal health, etc.

So considering this distributional hurdle to access of food the FAO's definition seems to be more appropriate as it covers almost all aspects of food security comprehensively. Furthermore, the (FAO2006, FAO2017) classified food security into four pillars which includes the availability of food, access to food, food stability, and utilization of food which are aligned with Sustainable Development Goals (SDGs). The food Availability emphasizes on availability and types of calories at the individual and national level. The availability pillar based on 5 indicators including average dietary energy supply adequacy, average value of food production, and share of dietary energy supply derived from cereals, roots and tuber, average protein supply and Average supply of protein of animal origin. The access of food contains those variables to measure the physical infrastructure needed to supply food to market, and other individual level indicators which measures either people could access the required calories per day. This includes factors such as rail density, GDP per capita, domestic food price index, prevalence of food security in total population and prevalence of undernourishment etc.

Food Stability measures the dependence on the imports of food products, variability in domestic prices, and variation in cultivable irrigated land etc. The indicators to measure the food stability are cereal imports dependency ratio, the Percentage of arable land equipped for irrigation value of food imports over total merchandise exports, domestic food price volatility, and per capita food supply variability. The pillar of utilization captures anthropometric indicators either people are able to use available calories etc. The relevant indicators including wasting, stunting, and low weight among children are used to measure the utilization of food. FAO uses access to sanitation facilities, the percentage of underweight children who are under 5 years of age, and the prevalence of anemia among women who are pregnant etc. to measure this pillar of food security.

\section{Conflict}

As conflict is not a straightforward concept to define, various parameters have been used to measure it in empirical literature. The battle deaths seem to be most common criterion researchers used to study the conflict in relation with any other variable. Weezel, (2017) estimating the relation of Conflict with food security has defined the conflict as a contested incompatibility concerning government and/or territory between two parties, one of which is the government, and where armed force has led to at least 25 battlerelated deaths. By using this definition very small incidents of violence where fatality remains below 25 fatalities will not be included in the dataset used for conflict. In this regard the data from Uppsala Conflict Database which is an appropriate database available to study the conflict. This data has been generated by department of Peace and Conflict Research, Uppsala University and the Centre for the Study of Civil War at the Peace Research Institute Oslo (PRIO) collaboratively which covers all conflicts from 1946 to 2018. Although many studies can be found which have used correlates of wars (COW) data base for conflict study but it doesn't give a closer look about conflict as COW datasets on war use the relatively high threshold of 1,000 battle-deaths. The Uppsala dataset on armed conflict has a lower threshold, 25 annual battled deaths (gleditsch, et all 2002)

\section{Theoretical and Empirical Literature Explaining the Nexus of Food Security and Conflict}

The plausible link of conflict with food security in theoretical account found to be distinctly explained in 
the literature. The negative impacts of conflict on food security might be explain in account of three dimensions of food security specified by FAO (2006) i.e. availability, access, and access. Verpoorten P. S., 2010) Muñoz-Mora, (2017) and Justin George,( 2019) explaining this negative association of conflict with food security suggests that conflict could impact the availability through its impact on agricultural production by reducing agricultural productivity and output because it might limit the labor supply to farm, and reduce access to land used for production. In addition to that it can impact various social and economic support systems for agricultural production. If conflict sustain it might affect the income of households leading the to limit the stock of crops and livestock which eventually affects the availability of food. The most recent studies which explain the interaction of conflict and food security found to be systematic, diverse and using modern methodological approaches to study this causal link. (Verpoorten, 2009); (Rockmore, 2015)) elaborate that due to the adverse impacts of conflict on supply of labor, limiting access to cultivable land, unavailability of credit, theft and destruction agriculture production may drop substantially in conflict affected regions. In most of the cases the decline in food production caused by physical destruction of crops, abandonment of farming land and crops and negative impacts of all these on investment could lead to a significant decline in farm production in conflict affected regions. (Teodosijević, (2003) states that despite being less affected sector than industry per-capita the production of agricultural output declined by 1.5 percent per year due to conflict. The production of Food usually reduces, or collapses in some cases, may leads to hunger and starvation consequently forces large numbers of people to migrate. It could possible that Food aid to some extent buffers foodintake levels but per-capita-per-day calorie availability does fall by an average of about $7 \%$ due to conflict. Food could be frequently used as a weapon during the period of conflict. The devastating outcomes of conflict such as destruction of infrastructure in rural areas, the loss of crops in line with loss of livestock, the use of land-mines, deforestation, and massive displacement of population could lead to the problems of food security in long term.

Similarly, the conflicts can affect the access to food both economically and physically due loss of income and limiting production, hoarding and suspension of supply due to hostility in conflict affected regions. (P Justino, 2014) suggests that associated economic contractions crumble public finances, which might diminish, or fully disrupt (in extreme cases) the mechanism of social protection. Due to suspension of business activity in conflict ridden countries the unemployment tends to increase which might limit the access to food if social protection mechanism is weak or doesn't exist in most of the cases. The conflict at micro level could cause the loss of business activities which could affect income providers such as small firms, farms, markets, schools, churches, mosques etc. Apart from limiting the access to food economically the conflicts tend to impact the access to food physically by destroying the infrastructure such as bridges, roads and farm markets which makes food inaccessible for the people living in conflict ridden countries.

Moreover, conflicts can affect utilization of food which can be measure by anthropometric indicators such as calories intake etc. These anthropometric measures including wasting, stunting, and low weight among children are seems to be significantly associated with conflict. (Martin, Stojetz, 2018) elaborate adverse short-term effects on nutritional status of children exposed to conflict. Most of these evidences found for anthropometric outcomes which might be associated with issues such as, stunting, malnutrition, and wasting etc. (Tom Bundervoet, 2009) explains that children ( 0-5 years) born in civil war affected regions, have significantly lower HAZ scores (that assess the stunting) than those born in non-conflict regions.

The empirical literature while explaining the nexus of conflict-food security gives a mix insight though most of the studies discuss the adverse effect of conflict on food security. (Anna D'Souza, 2012) investigates the relationship between conflict, food security, and food price shocks. Using data from nationally-representative household survey for food security and geo-coded data on violence for conflict, the study reveals the variations in food insecurity and conflict for Afghanistan. The evidence suggests that households in the provinces having higher levels of conflict related reduction in food security than 
the provinces experiencing lower levels conflict. This study might closely capture this relation of food security and conflict as it is based on primary household data from Afghanistan, an intensely conflict ridden country in the region.

Weezel, 2017) using the data, of 106 countries from the diverse regions of the world during 19610-2011, estimated the impacts of conflict on food security. Using the dietary energy supply (DES) as a proxy for food security the results reveal that conflict during this period found to be correlated with lower food security. The results also revealed that conflicts for government power are correlated with a reduction in dietary energy supply (DES) at national level. Martin-Shields \& Stojetz (2018) can be considered as most recent contribution in literature explaining the food security-conflict nexus both in theoretical as well as empirical accounts. Apart from emphasizing on the issue of indigeneity that identify the pairing between food security and conflict, this study mads some contributions. For instance, it defines both conflict and food security using the standardized databases, and explain how at the micro and macro levels the other intervening factors could influence this relationship of food security and conflict. It explains the casual linkage between food security and conflict comprehensively supported by evidences from recent empirical literature. Moreover, it highlights policy-affecting data gaps to suggest the way forward to improve the existing literature and data which might support policy making.

So after thoroughly reviewing the empirical literature explaining the interaction between food security and conflict few observations have to be considered. First much of the literature explaining this nexus of food security found to be unsystematic, lake diversity and inclusivity in nature. Second much of the accessible empirical literature explains this link has been analyzed on the date from single country affected by conflict. Fewer studies such as Weezel, (2017) investigate this relation which is based cross countries analysis. This might reflect the holistic view of the food security and conflict nexus as both conflict and none conflict ridden states from diverse regions are included in the sample. In this regard the literature is lacking the empirical analysis of this relation in regional account particularly in context south Asian region. Considering the exemptions such (Anna D'Souza, 2012) which analyzes the relation between food security and conflict for Afghanistan, none of the studies found in literature which explain this relation for conflict ridden south Asian region. This study might bridge this gap in empirical literature.

\section{Data and Methodology \\ Data}

Due to the multitude affect from the factors might influence the supply and demand of food, the measuring food security becomes challenge. Since this study investigate the relation between conflict and utility of food rather than any other pillar of food security the Dietary Energy Supply (DES) seems to be more suitable variable as compare to any other one. So we use the dietary energy supply (DES) as proxy variable for food security. DES will be used in terms of kilocalories intake (day/per capita) for selected samples of countries during 1990-2017. DES has been widely used to capture the utilization of food in literature. Cafiero, (2013) Weezel, (2017) have used in their studies investigating the food security in relations with other variables such as conflict etc. The variable of DES calories/ per day/per capita can be measured by taking total food supply available in the country for domestic use and dividing this with the total population of the same country. Moreover, the food supply available for domestic use can be measured by adding the imports of food to the total food production available at national level and subtracting food exports (if any), as well as adjusting the changes in available stocks. This variable accounts for various channels that influence food supply that might affect the food security in country. The data for Dietary energy supply for calories per day per capita can be obtained from FAO database available from 9161 to 2017. We have obtained the data of DES for selected south Asian countries from 1990-2017 from FAO Balance sheet which has been updated till 2017.

The data for conflict has been taken from Uppsala Conflict Data Program has been generated by department of Peace and Conflict Research, Uppsala University and the Centre for the Study of Civil 
War at the Peace Research Institute Oslo (PRIO) collaboratively which covers both internal and external, conflicts from period 1946 to the present. Although as mentioned above there many researchers in past have used correlates of wars (COW) data base for conflict study but it doesn't give a closer look about conflict because this dataset uses the high threshold relatively. The COW datasets uses of 1,000 battled-deaths as compare to Uppsala dataset which has a lower threshold of 25 battled deaths annually (gleditsch, et all 2002) hence gives a closer piture of conflict. We have used the data coding as 1 in case battled deaths are more than 25 in a year and 0 otherwise.

\section{Methodology}

Since the data for both the Dietary Energy supply a proxy of food security and Conflict has been obtained for the panel of six south Asian countries, it might pose some estimation and inference problems such as heteroscedasticity, autocorrelation and cross correlation in cross section units at the same point in time. Literature in such cases suggest to use the fixed effect and the random effect techniques which might deal with these estimation problems. How to opt for an appropriate model between fixed effect and random effect can be tackled by applying the Hausman test. Justin George,( 2019) used the same to estimat the empirical relationship between food security and conflict. The functional form of the will take place like this.

Calorie Intaketit $=\beta i+\beta 1$ Calorie Intakeit $-1+\beta 2$ Conflictit $+\beta 3$ Conflictit $-1+\mu$ it

While Calorie intake is the Dietary Energy supply per day per capita which is the proxy of food security while Conflict variable as defined above is the dummy as 1 in case battled deaths are more than 25 in a year and 0 otherwise.

\section{Results and Discussion}

In order to apply the fix random effect due to the reason mentioned above the first step is the selection of an appropriate panel model among the three types Pool OLS, the fix affect model and the random effect model. First type is a model with variant coefficients as well as variant intercepts, second type uses the similar coefficients but essentially different intercepts and third type of model has invariant coefficients and intercepts. In order to select one from the first two we applied F test which suggest to skip the pooled OLS and select one among fixed effect model and random effect model for the selected sample. Then we applied Hausman test which suggest to apply fixed effect model for the sample. The results of Hausman test are given in table 3 in Apendix. The chi-square value rejects the null hypothesis hence suggests the fix effect model is more appropriate for the estimation.

Table. 1 Cross-section Fix effects

\begin{tabular}{|l|l|l|l|l|}
\hline Variable & Coefficient & Std. Error & t-Statistic & Prob. \\
\hline & & & & \\
\hline C & 170.8531 & 73.29381 & 2.331071 & 0.0211 \\
\hline FOODSECURITY(-1) & 0.934229 & 0.030568 & 30.5627 & 000 \\
\hline CONFLICT & -26.6409 & 13.94044 & -1.91106 & 0.0579 \\
\hline CONFLICT(-1) & 11.51775 & 14.10865 & 0.816361 & 0.4156 \\
\hline & \multicolumn{5}{|l}{} \\
\hline R-squared & 0.94844 & & \\
\hline Adjusted R-squared & 0.945744 & & \\
\hline F-statistic & 351.8044 & \\
\hline Prob(F-statistic) & 0000 & & \\
\end{tabular}

*Dependent Variable: Food security (Calories intake/ day/per capita)

In table 2 the results for the fix affect model are illustrated. The probability of F-stats indicates that overall model is Significant while R2 shows that $94 \%$ variations in dependent variable are explained by the exploratory variables. So it might be concluded that the model is statistically significant and 
explaining enough cross country variations. The t-statistics probability of all explanatory variables shows that all coefficients except the variable which represents one-year lag period of conflict are statistically significant at 5\% level of significance. The regression results in Table.1 for Equation 1, where the (Calories intake/ day/per capita) is regressed on the explanatory variables such as the lag of calories intake (kca/day/capita), conflict, and temporal lag of conflict. The model in this case includes all types of conflict at the threshold of 25 battled deaths as defined by UCDP/PRIO. The coefficient of conflicts has negative sign with probability 0.057 which shows during the onset of conflict the calories intake (kca/day/capita) decrease 26 on average in year. On the other hand, the variable for one lag period of conflict is statistically insignificant despite has positive sign. So it might be presumed that conflict in selected sample of south Asian countries is adversly related with food security. In this regard the results might found to be consistent with Anna D'Souza, (2012) and Weezel, (2017) which reveal the same empirical association of onset of conflict with food security.

\section{Conclusion}

This study aims to investe the plausible link of food security and conflict for six south asian countries which have experinced conflict since 1990s or still have the ongoing conflicts. Some of these countries are declared as food insecure by FAO. The empirical literature explaining this nexus of food security and conflict has been analyzed on the date from single country affected by conflict. Fewer studies investigate this relation which is based cross countries analysis. This might reflect the holistic view of the food security and conflict nexus as both conflict and none conflict countries from diverse regions of the world are included in the sample. In this regard the literature is lacking the empirical analysis of this relation in regional account particularly in context south Asian region. Moreover, none of the studies found in literature which explains this relation for conflict ridden south Asian region. This study might bridge this gap in empirical literature. Using the data from FAO for Dietary Energy Supply (DES) a proxy for food security and battled deaths for Conflict from Upsala conflict database a panel of six south Asian countries has been analyzed. Using fix effect model the results revealed that that conflict in selected sample of south Asian countries is negatively associated with food security. The results might be consistent with some recent empirical studies investigating the same relationship from other regions of the world. The study has identified some gaps which can used for future research. First the empirical analysis for of food security and conflict relation in bi directional context can be carried out for the same sample of selected countries.

\section{References}

Anna D’Souza, D. J. (2012). Conflict, Food Price Shocks, and Food Insecurity: The Experience of Afghan Households . IZA Discussion Paper No. 6621.

Cafiero, C. (2013). What do we Really Know About Food Security? NBER WORKING PAPER.

Cindy Holleman, J. J. (2017). Sowing the seeds of peace for food security, Disentangling the nexus between conflict, food security and peace. ROOM: FAO.

Justin George, A. A. (2019). Armed conflicts and food insecurity: Evidence from Boko Haram's attacks. American Journal of Agricultural Economics, 8-11.

Karyn Havas, M. S. (2011). Food security: its components and challenges . International Journal of Food Safety Nutrition and Public Health.

Muñoz-Mora, P. V.-M. (2017). Returning Home after Civil War: Food Security and Nutrition among Burundian Households. Journal of Development Studies.

NILS PETTER GLEDITSCH, P. W. (2002). Armed Conflict 1946-2001: A New Dataset. Journal of Peace Research.

P Justino, J. T. (2014). Households amid urban riots: The economic consequences of civil violence in India. Journal of Conflict Resolution. 
Rockmore, M. (2015). Conflict and agricultural portfolios: Evidence from Northern Uganda. Working paper.

Stojetz, C. M.-S. (2018). Food security and conflict Empirical challenges and future opportunities for research and policy making on food security and conflict. FAO AGRICULTURAL DEVELOPMENT ECONOMICS.

Teodosijevic, S. B. (2003). Armed conflicts and food security. ESA Working Paper No. 03-11 Agricultural and Development Economics Division, FAO.

(2019). THE STATE FOOD SECURITY AND AGRICULTUR. ROOM: FAO.

(1996). THE STATE FOOD SECURITY AND AGRICULTURE. ROOM: FAO.

(2006). THE STATE OF FOOD AND AGRICULTURE. ROOM: FAO.

(2017). THE STATE OF FOOD AND AGRICULTURE. ROOM: FAO.

Tom Bundervoet, P. V. (2009). Health and Civil War in Rural Burundi. Journal of human Resources.

Verpoorten, M. (2009). Household coping in war- and peacetime: Cattle sales in Rwanda, 1991-2001. Journal of Development Economics.

Verpoorten, P. S. (2010). The Impact of Armed Conflict on Economic Performance. Journal of Conflict Resolution.

Weezel, S. v. (2017). Food security and armed conflict: a cross-country analysis. FAO AGRICULTURAL DEVELOPMENT ECONOMICS . 


\section{Appendix}

Table. 3

\begin{tabular}{|l|l|l|l|}
\hline Test Summary & $\begin{array}{l}\text { Chi-Sq. } \\
\text { Statistic }\end{array}$ & $\begin{array}{l}\text { Chi-Sq. } \\
\text { d.f. }\end{array}$ & Prob. \\
\hline $\begin{array}{l}\text { Cross-section } \\
\text { random }\end{array}$ & 7.174724 & 3 & 0.0665 \\
\hline
\end{tabular}

